\title{
Documenting Response To COVID-Individual and Systems Successes and Challenges: A Longitudinal Qualitative Study
}

Natasha Shaukat ( $\square$ natasha.shaukat@aku.edu )

Aga Khan University Hospital https://orcid.org/0000-0001-7002-0814

Daniyal Mansoor Ali

Aga Khan University Hospital

Butool Hisam

Aga Khan University Hospital

Sheza Hassan

Aga Khan University Medical College Pakistan

\section{Rubina Barolia}

Aga Khan University Hospital

\section{Badar Afzal}

Aga Khan University Hospital

\section{Abdus Salam Khan}

Shifa International Hospital

\section{Meher Angez}

Aga Khan University Medical College Pakistan

Junaid Razzak

Johns Hopkins University

\section{Research}

Keywords: COVID-19, frontline healthcare workers, individual-level challenges, health system-level challenges, hope for the future, prospective longitudinal qualitative study.

Posted Date: June 11th, 2021

DOI: https://doi.org/10.21203/rs.3.rs-594415/v1

License: (1) (1) This work is licensed under a Creative Commons Attribution 4.0 International License. Read Full License 


\section{Abstract \\ Background}

This feasibility study aimed to assess the use of WhatsApp for qualitative data collection to document the evolution of perceptions of frontline healthcare workers (FHCW) regarding their wellbeing and the quality of health systems' response to the COVID-19 pandemic over four months.

\section{Methods}

This was a prospective longitudinal qualitative study conducted during the four months coinciding with the peak and trough of the first wave of the COVID-19 pandemic (June-September 2020). We approached frontline healthcare workers (physicians and nurses working in emergency departments) in two hospitals using the WhatsApp group of the Pakistan Society of Emergency Physicians (PSEM). We introduced the study and obtained consent using a google consent form. Each participant was asked to self-record their perception of their personal wellness and their level of satisfaction with the quality of their hospitals' response to the pandemic. Each participant sent their voice notes/audio-recording to a central WhatsApp number. We transcribed and analysed the recordings and identified themes and sub-themes, and the changes to these themes over six months.

\section{Results}

We invited approximately $200 \mathrm{FHCWs}$ associated with PSEM to participate in the study. Of the 61 who agreed to participate, 27 completed the study. A total of 149 audio recordings were received and transcribed. Three themes and eight sub-themes have emerged from the data. The themes were individual-level challenges, health system-level challenges, and hope for the future. Sub-themes for individual-level challenges were: fear of getting or transmitting infection, financial stressors, stress due to turning away those patients who need care, anxiety due to the general public's lack of compliance with preventive measures, physical exhaustion, and fatigue. For the healthcare system, sub-themes were: issues with logistics and management of the hospital/healthcare system and lack of focus on providing air conditioning to address heat due to PPEs and sub-themes under hope for the future were the improved disease knowledge and vaccine development.

\section{Conclusion}

Despite a lower level of completion, our study identified possible use of a ubiquitously available mobile app to collect longitudinal real-time data from FHCWs during the initial period of the pandemic. The overall perceptions and experiences of FHCWs evolved from negative to positive as the curve of COVID19 went down. 


\section{Background}

The world has been battling with the COVID-19 pandemic since December 2019.(1, 2) As of May 26, 2021, the global pandemic has infected 164 million people worldwide while causing 3.4 million deaths.(3-5) Pakistan also confirmed its first COVID-19 case on February 26, 2020, with over 0.9 million confirmed cases and 21,000 deaths by May 26, 2021.(6)

COVID-19 pressurized and crippled healthcare systems across the world.(7) It exposed gaps in public health response and pandemic preparedness even in countries previously considered high performers.(8, 9) Healthcare services worldwide struggled to respond to the evolving crisis with the Frontline Healthcare Workers (FHCWs) battling the pandemic at tremendous personal risk, often with limited resources.(1013) FHCWs wellness encompasses physical, mental, and spiritual health and depends on several factors, including stress and burnout.(14,15) Stressors include day-to-day hospital issues, long working hours, stressful shifts and heavy workload, staff shortages, Personal Protective Equipment (PPE) and supplies shortages, and personal and family pressures.(16) FHCWs suffer psychological distress, anxiety, increased stress, insomnia, depressive symptoms, anger, fear, and post-traumatic stress disorders.(1621) As the FHCWs and systems adapt to the "new normal," the prolonged crisis response will lead to longlasting disruption of the overall wellbeing of FHCWs.(15)

Given the evolution and varying nature of the pandemic, we anticipate the stressors, challenges, and issues to change with time, and data identifying FHCW perceptions may not capture the evolution of the perception over time. Unfortunately, very few longitudinal studies have been conducted among healthcare workers, and none in the low- and middle-income countries (LMICs) to capture system and FHCWs challenges faced on a day-to-day basis, their coping mechanisms, and the impact on the overall wellbeing of FHCWs. For example, a recent longitudinal study of American emergency physicians demonstrated that stress levels decreased with time.(22) On the contrary, a Japanese longitudinal study showed persistent high levels of stress amongst HCWs.(23) Furthermore, there is a vacuum of longitudinal qualitative knowledge during the life of a pandemic. A longitudinal qualitative study is needed to provide deeper insights into the evolution of personal experiences, complex emotions, and feelings.

This global pandemic is occurring in a time of immense technological advancements. The paradigm shift towards digital health solutions in COVID times is revolutionary.(24) Digital tools can be handy in supporting research in these unprecedented times. The extensive use of smartphones and instant messaging (WhatsApp) has become a global phenomenon. WhatsApp is an easy-to-use platform for capturing and generating qualitative data.(25) This means of communication provides several options to participants for self-expression (written, audio, video). They can communicate in real-time as well as asynchronously.(24) We tested the feasibility of using WhatsApp for qualitative data collection to document the evolution of perceptions of frontline healthcare workers (FHCW) regarding their wellbeing and the quality of health systems' response to the COVID-19 pandemic over four months in Pakistan. 


\section{Methods}

\section{Study Setting}

Pakistan is the sixth most populous country globally, with a population of over 212 million people. This study was conducted through the platform of the Pakistan Society of Emergency Medicine (PSEM). PSEM is a non-profit professional medical platform representing professionals working in Emergency Medicine. It aims to develop and promote the field of emergency medicine in Pakistan.

\section{Study Design}

We conducted a prospective longitudinal qualitative study during the first wave of the COVID-19 pandemic in Pakistan for four months (June-September 2020). During this period, Pakistan experienced the peak of the first wave, followed by the flattening of the curve and ease of lockdown interventions.

\section{Study Population}

The study population comprised physicians and nurses involved in clinical service delivery in the EDs of two private sector tertiary care hospitals of Pakistan. The ED physicians and nurses in these two hospitals receive the most critically ill and sick patients. As front-liners, our study participants were directly responsible for initial resuscitation and stabilization of patients, initiate diagnosis, and initial management of acute patients.

\section{Eligibility Criteria}

Only those Emergency Medicine physicians and nurses directly involved in taking care of COVID-19 patients were included in the study.

\section{Sample Size}

We invited all (approximately 200) physicians and nurses associated with the Pakistan Society of Emergency Medicine to participate in the study. Initially, 61 people were enrolled in the study; however, 27 remained till the end of the study.

\section{Sampling Technique}

A convenience sampling technique was used to select the healthcare workers. They were enrolled through the platform of the Pakistan Society of Emergency Medicine (PSEM). The participants were approached through the WhatsApp group of PSEM. A google consent form was shared to invite and obtain consent. Those participants who consented to participate throughout the length of the study were enrolled. Secondly, to increase participation, we reinforced the participation using senior physicians and nurses in the emergency departments.

\section{Data Collection Methods}


We utilized two methods of data collection: self-audio recordings by participants on WhatsApp and telephonic interviews. The participants were approached through the WhatsApp group of PSEM and emails of individuals. We sent the study guide via WhatsApp to the participants to self-record the answers. The study guide was followed by a detailed WhatsApp text message \& audio-recording to: invite and welcome the participants, introduce the study and guide them about the data collection process. The message also covered the purpose, nature of the study, what, when, and how to record the audio message and send the audios. We shared a WhatsApp number and requested the participants to self-record short audio messages (four to five minutes) on their mobile phones after every shift's end and send them as voice notes/audio recordings via WhatsApp. To ensure the participants kept sending the audio recordings, we sent individual reminders on WhatsApp. Initially, the participants sent two to three audio recordings per week (depending on the number of shifts), with some sending it once a week. Those participants who were unable to send audios were interviewed telephonically once a week. Overall, we conducted 38 telephonic interviews.

\section{Study Guide}

A study guide was prepared and consisted of semi-structured questions. In addition, participants were asked to record audios by answering these open-ended questions:

1. How was your day today? Please describe how are you feeling physically and emotionally today?

2. How was your departments' response to COVID-19 today? What went well? What could have been better?

3. What are you most worried about today?

4. Is there anything else that you want to share?

\section{Data Analysis}

Audio recordings were sorted by serial numbers and saved date-wise at the end of each day. Voice notes were directly uploaded and saved on Microsoft SharePoint Software. At the end of data collection, the audio recordings were transcribed and translated. These transcripts were uploaded and analyzed via qualitative data analysis software MAXQDA 2020. Initially, codes were generated based on issues identified, and data were coded based on the participant's response. Then, thematic analysis was carried out, and similar codes were categorized to develop themes and sub-themes based on Creswell criteria. (26) Finally, we captured the evolution and changes in perceptions over time and grouped the sub-themes into early and late perceptions.

\section{Results}

The 27 participants sent in a total of 149 audio recordings. Our analysis identified three themes and eight sub-themes, as shown in Table 1. 
Table 1

Themes and sub-themes emerging from the data.

\begin{tabular}{|ll|}
\hline Themes & Sub-Themes \\
\hline $\begin{array}{l}\text { Individual-level } \\
\text { Challenges }\end{array}$ & Fear of getting infected or transmitting the disease to loved ones \\
\hline Financial stressors \\
\hline Stressed in treating/turning away seriously ill COVID-19 patients \\
\hline $\begin{array}{l}\text { Anxiety due to people's lack of compliance with COVID-19 SOPs } \\
\text { Health System } \\
\text { Challenges }\end{array}$ & $\begin{array}{l}\text { Infrastructure, logistics, management, and communications response of } \\
\text { the hospital } \\
\text { Lack of proper room temperature /air conditioner due to hot weather } \\
\text { Hope for future }\end{array}$ \\
\hline $\begin{array}{l}\text { Improved disease knowledge and vaccine development trials give hope } \\
\text { Hopeful future as the patient burden decreased. }\end{array}$ \\
\hline
\end{tabular}

\section{Theme 1: Individual-level Challenges}

The physicians and nurses reported several mental and physical health challenges. These health challenges evolved with time as the COVID-19 pandemic progressed. Commonly occurring sub-themes included fear of getting infected or transmitting the disease to loved ones, financial stressors, guilt because of turning away patients due to hospital capacity issues, concerns due to lack of compliance by the general public, and their refusal to follow COVID-19 standard operating procedures. The group also identified exhaustion, fatigue, and body aches due to heavy PPE use.

\section{Sub-Theme 1.1: Fear of getting infected or transmitting the infection to loved ones}

\section{Early perceptions}

As the pandemic reached its peak in June-July, 2020, in Pakistan, most FHCWs were worried and feared that they might get infected while working in the COVID areas of the hospitals. They thought they were at high risk of getting infected as there was an increased patient load, a large number of sick patients arriving at once, patient volume exceeding the bed capacity, and managing patients in congested areas. They were also afraid of infecting their families, loved ones, and friends. Those who had elderly and young children at home were particularly fearful of transmitting infection.

"The main fear I have is that if I catch this infection, I might get healthy again, but if my parents catch it, since they have multiple comorbidities, I might lose them." (WhatsApp Audio 2020-06-04 at 4.15 PM). 


\section{Late perceptions}

As the pandemic progressed, in August and September 2020, the fear of infection reduced. Most FHCWs were less anxious as they adapted to the new normal. Some of them said that the pandemic had ended, and COVID-19 did not exist anymore. Others were not worried because they were wearing full PPEs and felt protected. In addition, some believed they were unlikely to get infected as they had a strong faith in God.

However, this fear remained high for some of the workers even during the later stage of the pandemic.

\section{Sub-Theme 1.2: Financial stressors}

\section{Early perceptions}

As the pandemic progressed and its associated lockdowns were implemented, its economic repercussions were felt by all. Many participants reported being under stress amidst news of salary reductions. People were worried about how will they feed their families and run their houses. In addition, as the overtime pays were disallowed, participants were worried about making their ends meet.

"We are worried that our salaries will be reduced and it will make it difficult for us to run our houses." (WhatsApp Ptt 2020-08-10 at 09.43 PM)

\section{Late perceptions}

The fears and challenges related to salary reductions improved with time. FHCWs expressed their relief that they did not have to suffer from a significant financial burden. However, they felt upset as the overtime pays were removed.

Sub-Theme 1.3: Feeling of guilt as COVID-19 patients were turned away by hospitals when they reached maximum capacity

\section{Early perceptions}

During the peak months of June and July 2020, many FHCWs talked about feeling sad and guilty as the COVID-19 cases increased and the hospitals were unable to provide services to all the patients and had to refuse care to some of the patients. One of the participants said:

"It is a very painful thing to tell a critical patient that we cannot take you as our beds are full." (WhatsApp Ptt 2020-06-10 at 4.33 PM)

FHCWs spoke up about and attendants ' reactions to lack of beds. They felt disrespected and were often verbally abused when patients and families have difficulty obtaining a bed. One of the participants expressed:

Because we do not have space, we are now getting curses instead of getting good wishes like before. 


\section{Late perceptions}

Towards the end of August, the situation seemed to settle, with fewer participants reporting such negative interactions. Few even described receiving verbal appreciation from patients and their families for their hard work. With time people reported lessor anxiety as they adapted to the new normal.

\section{Sub-Theme 1.4: Concerned due to people's lack of compliance and denial of COVID-19 SOPs}

Almost all of the participants expressed their concern over public violations of COVID-19 SOPs. Nurses reported feeling 'disrespected' with all their hard work thrown to waste because the public was not following preventive measures (social distancing, face masks). This augmented the fear of predisposing the FHCWs to infection as well.

"It makes me sad that I am working for people as I am committed to my profession to serve humanity. And they are not even taking care of themselves. We are at risk." (WhatsApp Pt 2020-06-01 at 8.59 PM)

This concern was reported during the entire duration of data collection, and the trend remained unchanged.

\section{Sub-Theme 1.5: Exhaustion, fatigue, and body aches due to heavy PPE use}

Early perceptions

Almost all of the participants reported severe difficulties in wearing PPEs during the hot summer months of Karachi and Islamabad. The participants described experiencing headaches, dizziness, physical and mental exhaustion, and fatigue. Mostly they used the word "suffocated" particularly about the N95 masks, with many commenting that it was difficult to wear them all day long as it led to breathing difficulties. Many described having to take a break "just to breathe" from having worn PPE for an extended period.

"It is challenging to work on COVID patients while wearing PPE. I was profusely sweating and very tired. And it is very difficult to wear N95 all the time and breathe properly. I was suffocating, but still, I managed to do my duty." (WhatsApp Ptt 2020-06-03 at 12.53 PM)

Late perceptions

This concern settled with time as they developed resilience. Towards the end, they mainly reported that they had adjusted to the physical stress of wearing heavy PPE. Despite the physical difficulties, the FHCWs appreciated the adequate and timely provision of PPEs.

\section{Theme 2: Health system challenges}


Data demonstrated one main sub-theme: Infrastructure, logistics, management, and communications response of the hospital.

\section{Sub-theme 2.1: Infrastructure, logistics, management, and communications response of the hospital}

\section{Early perceptions}

The number of patients increased rapidly in June/July '20. Beds filled up quickly, and due to a large number of patients in limited space, the staff had less space to move around. FHCWs felt that the designated COVID-19 zones needed improvements such as; installing proper curtains and railings to reduce infection transmission. FHCWs reported difficulty in communication as they were wearing full personal protective equipment (PPEs). They had to do donning and doffing procedures as they entered and left COVID-19 zones, making it hard to communicate with colleagues, write notes, and give orders. They expressed a need for improving communication strategies in the COVID/non-COVID zones. Some FHCWs talked about short supplies of BiPAP/ventilators hindering patient care and suggested stocking up supplies. Furthermore, as the patient workload increased, they faced extra burdened due to shortages in the health workforce who were also falling sick. The participants suggested better management of rosters and scheduling frequent breaks in between shifts to avoid burnout.

"One thing that is making me worried is how frequently we are being assigned here. It would be good if we can get a break and have a rotational schedule." (WhatsApp Ptt 2020-06-01 at 7.32 PM)

\section{Late perceptions:}

The FHCWs expressed relief and appreciated as the hospitals adapted over time by increasing the space and capacity of designated COVID-19 zones, the number of beds, the human resource, provided training in donning and donning of PPEs, improved management skills of critical patients, knowledge of the disease, and timely communication. In addition, they felt much safer as they received timely communication from the infectious disease department.

"The other best thing that the department did was to develop negative pressure rooms. They made a separate lounge where the COVID staff can take a break. There was no contact between the other staff and COVID staff. That was the best thing." (WhatsApp Audio 2020-06-07 at 7.20. PM).

\section{Another participant said:}

"We are getting proper instructions on a timely basis related to the care of COVID-19 suspected or confirmed patients and regarding our safety. We have a separate department in our hospital that is related to infectious diseases. And they are responsible for informing us about daily strategies to keep ourselves safe." (WhatsApp Audio 2020-05-31 at 7.36). 
They felt confident in their improved management skills. Finally, they felt happy in saving the lives of critical patients.

"We feel happy to see those patients surviving who we intubated. That is a personal win for us." (WhatsApp Audio 2020-08-31 at 10.26 PM)

While some FHCWs were appreciative of the hospital's improved response in accommodating more patients, with efficient triage system placed for COVID-19 patients, some FHCWs found slow discharge processes resulting in delays and longer length of stay. In addition, this backlog caused difficulty in accommodating newer patients, so the participants felt frustrated when they refused care to critical patients and wanted the hospital administration to have a better management plan instead of constantly diverting patients to other hospitals.

"There are delays in shifting patients which increases the burden in emergency and patient waiting time increases." (WhatsApp Audio 2020-06-01 at 10.52 AM)

\section{Theme 3: Hope for future}

Research findings demonstrated two sub-themes: Improved disease knowledge and vaccine development trials gave hope and a hopeful future as the patient burden decreased with time.

\section{Sub-Theme 3.1: Improved disease knowledge and vaccine development trials gave hope}

Many FHCWs felt positive about the improved knowledge and understanding of the disease and the virus. They also felt prepared and better equipped to fight COVID-19 as compared to the initial days, which were filled with fear and uncertainties.

"For this pandemic of COVID-19, we critical care staff working in ED have been taught for the patients proning which is helpful in moderate ARDS patient. So, we can make them not go in that severe ARDS. It was a useful session as we learned on simulation." (WhatsApp Ptt 2020-08-30 at 20 PM)

Similarly, the FHCWs were hopeful as several research projects were being done and several vaccines were undergoing trials. For some, this was very positive news and believed that this is the most important intervention to overcome the disease.

\section{Sub-Theme 3.2: Hopeful future as the patient burden decreased}

The FHCWs perceptions from stress and fear shifted towards relief and hope as the cases started to decrease. They said that the future looks positive as the number of patients is decreasing. They felt that they have been successful in beating COVID-19 until now, and it seems they will be able to recover fully from it. 


\section{Discussion}

COVID-19 pandemic has tested the resilience of individuals and the healthcare systems. We aimed to document the FHCWs individual journey and their perception of the health systems performance during the peak and trough of the first wave of the COVID-19 pandemic. It is the first qualitative longitudinal study in a real-time pandemic to capture healthcare workers evolution of perceptions.

There were several mental and physical health challenges expressed by the FHCWs as they worked on the frontline during the COVID-19 pandemic. In the initial days, the fear of getting infected and transmitting the infection to loved ones was extremely high. They believed they were at high risk as there was unprecedentedly high patient load, compromised bed capacity, lack of understanding of the disease, and uncertainty about patient outcomes. Similar concerns have been expressed in several studies from countries such as the People's Republic of China, Islamic Republic of Iran, Lebanon, Brazil, and Pakistan in expressed high fear of getting infected due to their jobs.(27-31)

We found a positive change as the number of cases during the first wave declined. The study participants attributed the improved perception to the availability of PPEs, protection due to God's blessings, and improved patient outcomes. In addition, early success led some to believe that COVID-19 did not exist anymore. Similarly, FHCWs expressed mental exhaustion, fear, stress, and anxiety during the initial peak period, which evolved into physical exhaustion, fatigue, tiredness, headaches, dizziness, and suffocation. Many of these physical symptoms were attributed to wearing PPE.

Health systems around the world were compromised in the face of the deadly pandemic. Similarly, Pakistan also faced tremendous challenges. During the initial/peak period, there was a lack of space and high patient volumes, and hospitals were put on diversion due to lack of space, difficulties in managing critical patients due to limited knowledge, difficulty in communication due to full PPE gear, shortage of human resource and lack of BiPAP/ventilators. Nearly most of the countries reported similar challenges. $(7,32)$

Furthermore, FHCWs shared several positive experiences. They took pride and expressed satisfaction in saving lives. Our participants felt optimistic and hopeful about the future outlook; the numbers had gone down significantly, improved disease knowledge and management, and vaccine trials were looking good.

Data collection during public health emergencies is a significant challenge. An important learning from this study is the potential role of WhatsApp for qualitative data collection during a crisis. We found that WhatsApp was an easy-to-use tool that generated a large amount of rich data in a relatively short interval. Moreover, since the data was self-generated, the resources required for data collection were limited, there was no researcher bias, and the role of social desirability was reduced. Also, the risk to the researcher was lower as they did not have to expose themselves to collecting data in the inpatient care area. Furthermore, most of the participants found it convenient, as they could record audios at a time of their choice. Our experience is in line with another study conducted on Syrian Refugees and host communities in Lebanon. (33) In addition, a qualitative media communication study reported similar advantages of instant 
messaging for qualitative data collection.(25) Our literature review did not identify any example of longitudinal data collection through WhatsApp during the COVID-19 pandemic and this adds to the literature regarding its potential use in the current pandemic and similar crisis.

Despite the self-recorded audio messaging through WhatsApp, it is important to discuss the challenges and limitations of such an approach. First, we found that as the study progressed, the number of selfrecorded audios decreased. The participants were asked why; they reported feeling tired due to heavy workload during their shifts and were too tired to take on an additional task. For these participants, we offered a telephonic interview over weekends and at the time of their convenience. We considered but decided not to offer any incentive for sharing recordings. In retrospect, a carefully selected incentive might have allowed for more consistent data sharing. Secondly, study participants felt that they did not have any particularly new data to report after each shift. We addressed this issue by changing the reporting frequency from each shift to reporting once a week. Thirdly, our study participants were all from

private sector tertiary care hospital EDs. Unfortunately, we could not get FHCWs from the public sector to participate in the study despite several attempts. The perception of public sector FHCWs might be different as resources are often limited, and the workload is high in these settings. Finally, we had to stop the data collection process after four months as the number of COVID-19 patients decreased, and the participants felt they had nothing new to report.

\section{Conclusion}

This longitudinal study outlines the individual and health system challenges and the evolution of healthcare workers' perceptions regarding the response to COVID-19 during the COVID-19 pandemic. This study highlights the most commonly faced challenges as perceived by the healthcare professionals, how individuals and systems coped with these challenges, and the strategies adopted to tackle this pandemic effectively. In addition, this study adds to the literature by sharing the experience of using WhatsApp for collecting real-time qualitative data. Moreover, this study is one of its kind, which provides learning opportunities as experienced first-hand by FHCWs during the pandemic.

\section{List Of Abbreviations}

COVID-19

coronavirus disease; FHCWs:Frontline Healthcare Workers; PPE:Personal Protective Equipment; LMICs:low- and middle-income countries; PSEM:Pakistan Society of Emergency Medicine; ED:Emergency Department.

\section{Declarations}

\section{Ethics approval and consent to participate}


The study was approved by The Aga Khan University Ethics Review Committee (ERC) and consent was obtained from all the participants prior to starting.

\section{Consent for publication}

Not applicable.

\section{Availability of data and materials}

The data that support the findings of this study are available from the corresponding author upon reasonable request.

\section{Competing interests}

The authors declare that they have no competing interest.

\section{Funding}

None.

\section{Authors' contributions}

NS and DMA contributed in the study design, data collection, data analysis, data interpretation, and writing of the manuscript. BH contributed in the study design, data interpretation, and writing of the manuscript. SH contributed in data interpretation, data translation and transcription. RB, BA, and ASK contributed in data interpretation and writing of the manuscript. MA contributed in data translation. JR contributed in the study design, data analysis, data interpretation, and writing of the manuscript and provided overall supervision. All authors read and approved the final manuscript.

\section{Acknowledgments}

We thank the Frontline Healthcare Workers (FHCWs) for taking out time from their busy schedules to participate in this study.

\section{References}

1. Technical guidance [Internet]. [cited $2021 \mathrm{Feb} 14]$. Available from: https://www.who.int/emergencies/diseases/novel-coronavirus-2019/technical-guidance.

2. Healthcare Workers. Information on COVID-19 | CDC [Internet]. [cited 2021 Feb 14]. Available from: https://www.cdc.gov/coronavirus/2019-nCoV/hcp/index.html.

3. Coronavirus Disease. (COVID-19) Situation Reports [Internet]. [cited 2021 Feb 14]. Available from: https://www.who.int/emergencies/diseases/novel-coronavirus-2019/situation-reports.

4. COVID-19 situation. update worldwide, as of week 5, updated 11 February 2021 [Internet]. [cited 2021 Feb 14]. Available from: https://www.ecdc.europa.eu/en/geographical-distribution-2019-ncov-cases. 
5. Dong E, Du H, Gardner L. An interactive web-based dashboard to track COVID-19 in real time. The Lancet Infectious diseases. 2020;0(0).

6. Two coronavirus cases confirmed in Pakistan. | Pakistan Today [Internet]. [cited 2021 Feb 14]. Available from: https://archive.pakistantoday.com.pk/2020/02/26/sindh-health-two-coronaviruscases-confirmed-in-pakistan-confirms-first-coronavirus-case-in-karachi/.

7. Giannopoulou I, Tsobanoglou GO. COVID-19 pandemic: Challenges and opportunities for the Greek health care system [Internet]. Vol. 37, Irish Journal of Psychological Medicine. Cambridge University Press; 2020 [cited 2021 Feb 15]. p. 226-30. Available from: /pmc/articles/PMC7287301/.

8. Lal A, Erondu NA, Heymann DL, Gitahi G, Yates R. Fragmented health systems in COVID-19: rectifying the misalignment between global health security and universal health coverage [Internet]. Vol. 397, The Lancet. Lancet Publishing Group; 2021 [cited 2021 May 26]. p. 61-7. Available from: https://pubmed.ncbi.nlm.nih.gov/33275906/.

9. el Bcheraoui C, Weishaar H, Pozo-Martin F, Hanefeld J. Assessing COVID-19 through the lens of health systems' preparedness: time for a change [Internet]. Vol. 16, Globalization and Health. BioMed Central Ltd; 2020 [cited 2021 May 26]. Available from: https://pubmed.ncbi.nlm.nih.gov/33213482/.

10. Coronavirus in Europe. Thousands of Health Workers Out of Action - The New York Times [Internet]. [cited 2021 Feb 14]. Available from:

https://www.nytimes.com/2020/03/24/world/europe/coronavirus-europe-covid-19.html.

11. Lin M, Beliavsky A, Katz K, Powis JE, Ng W, Williams V, et al. What can early Canadian experience screening for COVID-19 teach us about how to prepare for a pandemic? Canadian Medical Association Journal [Internet]. 2020 Mar 23 [cited 2020 Mar 27];192(PG-):cmaj.200305. Available from: http://www.cmaj.ca/lookup/doi/10.1503/cmaj.200305.

12. Koh D. Occupational risks for COVID-19 infection. Occupational medicine (Oxford, England) [Internet]. 2020 [cited 2020 Apr 2];70(1):3-5. Available from: http://www.ncbi.nlm.nih.gov/pubmed/32107548.

13. Coronavirus. has infected 8,000 healthcare workers in Pakistan so far [Internet]. [cited 2021 Feb 14]. Available from: https://www.geo.tv/latest/314386-coronavirus-has-infected-8000-healthcareworkers-in-pakistan-so-far.

14. Nagesh S, Chakraborty S. Saving the frontline health workforce amidst the COVID-19 crisis: Challenges and recommendations [Internet]. Vol. 10, Journal of Global Health. University of Edinburgh; 2020 [cited 2021 May 26]. Available from: https://pubmed.ncbi.nlm.nih.gov/32373323/.

15. Bansal P, Bingemann TA, Greenhawt M, Mosnaim G, Nanda A, Oppenheimer J, et al. Clinician Wellness During the COVID-19 Pandemic: Extraordinary Times and Unusual Challenges for the Allergist/Immunologist [Internet]. Vol. 8, Journal of Allergy and Clinical Immunology: In Practice. American Academy of Allergy, Asthma and Immunology; 2020 [cited 2021 May 26]. p. 17811790.e3. Available from: https://pubmed.ncbi.nlm.nih.gov/32259628/.

16. Shaukat N, Ali DM, Razzak J. Physical and mental health impacts of COVID-19 on healthcare workers: A scoping review [Internet]. Vol. 13, International Journal of Emergency Medicine. BioMed Central Ltd; 2020 [cited 2021 May 26]. Available from: https://pubmed.ncbi.nlm.nih.gov/32689925/. 
17. Xiao H, Zhang Y, Kong D, Li S, Yang N. The Effects of Social Support on Sleep Quality of Medical Staff Treating Patients with Coronavirus Disease 2019 (COVID-19) in January and February 2020 in China. Medical science monitor: international medical journal of experimental and clinical research [Internet]. 2020 Mar 5 [cited 2020 Mar 20];26:e923549. Available from: http://www.ncbi.nlm.nih.gov/pubmed/32132521.

18. Huang JZ, Han MF, Luo TD, Ren AK, Zhou XP. [Mental health survey of 230 medical staff in a tertiary infectious disease hospital for COVID-19]. Zhonghua lao dong wei sheng zhi ye bing za zhi = Zhonghua laodong weisheng zhiyebing zazhi = Chinese journal of industrial hygiene and occupational diseases [Internet]. 2020 Mar 4 [cited 2020 Mar 20];38(0):E001. Available from: http://www.ncbi.nlm.nih.gov/pubmed/32131151.

19. Chen Q, Liang M, Li Y, Guo J, Fei D, Wang L, et al. Mental health care for medical staff in China during the COVID-19 outbreak. The lancet Psychiatry [Internet]. 2020 Feb 18 [cited 2020 Mar 20]; Available from: http://www.ncbi.nlm.nih.gov/pubmed/32085839.

20. Kang L, Li Y, Hu S, Chen M, Yang C, Yang BX, et al. The mental health of medical workers in Wuhan, China dealing with the 2019 novel coronavirus. The lancet Psychiatry [Internet]. 2020 Mar 1 [cited 2020 Mar 20];7(3):e14. Available from: http://www.ncbi.nlm.nih.gov/pubmed/32035030.

21. Lai J, Ma S, Wang Y, Cai Z, Hu J, Wei N, et al. Factors Associated With Mental Health Outcomes Among Health Care Workers Exposed to Coronavirus Disease 2019. JAMA network open [Internet]. 2020 Mar 2 [cited 2020 Mar 27];3(3):e203976. Available from: http://www.ncbi.nlm.nih.gov/pubmed/32202646.

22. Baumann BM, Cooper RJ, Medak AJ, Lim S, Chinnock B, Frazier R, et al. Emergency physician stressors, concerns, and behavioral changes during COVID-19: A longitudinal study. Academic Emergency Medicine [Internet]. 2021 Mar 1 [cited 2021 May 26];28(3):314-24. Available from: https://pubmed.ncbi.nlm.nih.gov/33492755/.

23. Sasaki N, Kuroda R, Tsuno K, Kawakami N. The deterioration of mental health among healthcare workers during the covid-19 outbreak: A population-based cohort study of workers in japan. Scandinavian Journal of Work, Environment and Health [Internet]. 2020 [cited 2021 May 26];46(6):639-44. Available from: https://pubmed.ncbi.nlm.nih.gov/32905601/.

24. Sust PP, Solans O, Fajardo JC, Peralta MM, Rodenas P, Gabaldà J, et al. Turning the crisis into an opportunity: Digital health strategies deployed during the COVID-19 outbreak [Internet]. Vol. 6, JMIR Public Health and Surveillance. JMIR Publications Inc.; 2020 [cited 2021 May 26]. Available from: https://pubmed.ncbi.nlm.nih.gov/32339998/.

25. Kaufmann K, Peil C. The mobile instant messaging interview (MIMI): Using WhatsApp to enhance self-reporting and explore media usage in situ. Mobile Media and Communication [Internet]. 2020 May 1 [cited 2021 May 26];8(2):229-46. Available from: https://doi.org/10.1177/2050157919852392.

26. (No Title) [Internet]. [cited 2021 May 26]. Available from: http://www.ceil-conicet.gov.ar/wpcontent/uploads/2018/04/CRESWELLQualitative-Inquary-and-Research-Design-Creswell.pdf. 
27. Alizadeh A, Khankeh HR, Barati M, Ahmadi Y, Hadian A, Azizi M. Psychological distress among Iranian health-care providers exposed to coronavirus disease 2019 (COVID-19): A qualitative study. BMC Psychiatry [Internet]. 2020 Oct 7 [cited 2021 Feb 15];20(1). Available from: https://pubmed.ncbi.nlm.nih.gov/33028290/.

28. Cui S, Zhang L, Yan H, Shi Q, Jiang Y, Wang Q, et al. Experiences and psychological adjustments of nurses who voluntarily supported covid-19 patients in Hubei Province, China. Psychology Research and Behavior Management [Internet]. 2020 [cited 2021 Feb 15];13:1135-45. Available from: https://pubmed.ncbi.nlm.nih.gov/33312005/.

29. Góes FGB, da Silva ACSS, dos Santos AST, Pereira-Ávila FMV, da Silva LJ, da Silva LF, et al. Challenges faced by pediatric nursing workers in the face of the covid-19 pandemic. Revista LatinoAmericana de Enfermagem [Internet]. 2020 [cited 2021 Feb 15];28:1-9. Available from: https://pubmed.ncbi.nlm.nih.gov/32901774/.

30. Robertson E, Hershenfield K, Grace SL, Stewart DE. The psychosocial effects of being quarantined following exposure to SARS: A qualitative study of Toronto health care workers. Canadian Journal of Psychiatry [Internet]. 2004 [cited 2021 Feb 15];49(6):403-7. Available from: https://pubmed.ncbi.nlm.nih.gov/15283537/.

31. Sethi BA, Sethi A, Ali S, Aamir HS. Impact of coronavirus disease (COVID-19) pandemic on health professionals. Pakistan Journal of Medical Sciences [Internet]. 2020 [cited 2021 Feb 15];36(COVID19-S4). Available from: https://pubmed.ncbi.nlm.nih.gov/32582306/.

32. Turale S, Meechamnan C, Kunaviktikul W. Challenging times: ethics, nursing and the COVID-19 pandemic. International Nursing Review [Internet]. 2020 Jun 1 [cited 2021 Feb 15];67(2):164-7. Available from: https://pubmed.ncbi.nlm.nih.gov/32578249/.

33. Document - UNDP Innovation. "Speak up via WhatsApp" Project-Whatsapp Guide book [Internet]. [cited 2021 May 26]. Available from: https://data2.unhcr.org/en/documents/details/67580. 